\title{
Seasonal Carbohydrate Dynamics and Climatic Regulation of Senescence in the Perennial Grass, Miscanthus
}

\author{
Sarah Jane Purdy • Jennifer Cunniff • Anne Louise Maddison • Laurence Edmund Jones • \\ Tim Barraclough • March Castle • Christopher Lyndon Davey • Charlotte Melanie Jones • \\ Ian Shield • Joe Gallagher • Iain Donnison • John Clifton-Brown
}

Published online: 1 July 2014

(C) The Author(s) 2014. This article is published with open access at Springerlink.com

\begin{abstract}
Miscanthus is a perennial energy grass predominantly used for combustion but there is increasing interest in fermenting the cell-wall carbohydrates or green-cutting for soluble sugars to produce bioethanol. Our aims were to: (1) quantify non-structural carbohydrates (NSC), (2) observe the timing of seasonal shifts in the stems and rhizome, and (3) identify developmental and/or climatic conditions that promoted carbohydrate remobilization from the stems to the rhizome during senescence. Two genotypes of Miscanthus sinensis, a Miscanthus sacchariflorus and a Miscanthus $\times$ giganteus were grown at replicated field sites in Aberystwyth, West Wales and Harpenden, South East England. NSC were quantified from the rhizome and aboveground organs and then correlated with climatic data collected from on-site weather stations. PAR and maximum daily temperatures were higher at Harpenden throughout the year, but daily minimum temperatures were lower. Senescence was accelerated at Harpenden. Carbohydrates were retained within the stems of nonflowering genotypes, at both sites, in winter and were still present after a frost event to $-2{ }^{\circ} \mathrm{C}$. Rhizome starch concentrations were at least equal to the previous winter's levels (February 2011) by September. Lower daily minimum temperatures accelerate the rate of senescence and warmer daily maximum temperatures cannot counteract this effect. At current yields, $M$. $\times$ giganteus, could produce $0.7 \mathrm{t} \mathrm{ha}^{-1}$ of NSC in addition to ligno-cellulosic biomass in November but with concerted breeding efforts this could be targeted for
\end{abstract}

\footnotetext{
S. J. Purdy $(\triangle) \cdot$ A. L. Maddison • L. E. Jones · C. L. Davey •

C. M. Jones · J. Gallagher · I. Donnison · J. Clifton-Brown Institute of Biological, Environmental and Rural Sciences (IBERS), Aberystwyth University, Gogerddan, Aberystwyth, Ceredigion SY23 3EE, UK

e-mail: sap@aber.ac.uk

J. Cunniff $\cdot$ T. Barraclough $\cdot$ M. Castle $\cdot$ I. Shield

Rothamsted Research, Harpenden, Hertfordshire AL5 2JQ, UK
}

improvement as has been achieved in other crops. Shifting harvests forward to November would not leave the rhizome depleted of carbohydrates.

Keywords Bioenergy · Carbohydrates · Genotypes · Miscanthus $\cdot$ Rhizome $\cdot$ Senescence $\cdot$ Temperature · Temperature $\cdot$ Climate

\section{Introduction}

Miscanthus is predominantly used for combustion as a substitute for coal, but with the development of ligno-cellulosic fermentation technologies may also offer an alternative feedstock for the production of transport and aviation fuels [1-3]. Miscanthus is harvested in late winter/early spring when nutrient remobilization (senescence) has taken place and the crop is dry. For combustion, this practice is advantageous because the retention of mineral elements can leave damaging residues in burners [2] and a low moisture content negates the need for a drying stage prior to combustion. This is also advantageous for the long-term sustainability of the plant as nutrients required to fuel the next seasons' growth are recycled from the stems back to the rhizome during senescence [4]. However, for fermentation (bio-conversion) purposes, biomass with high moisture contents can be efficiently utilized [5].

As a member of the Poaceae family, Miscanthus is phylogenetically closely related to two other important energy and food crops; Saccharum sp. (sugarcane) and Zea mays (maize) [6]. Unlike sugarcane and maize, Miscanthus is not harvested for soluble sugars (sugarcane) or starch (maize) instead it is harvested for the structural cell-wall polysaccharides. Consequently, the structural carbohydrate composition of different genotypes of Miscanthus has been the subject of a number of studies [2, 7-9], but the non-structural carbohydrates (NSC) are less documented. The metabolic processing and storage of 
NSC in plants underpins all yield and biomass traits [10] and so describing their form and abundance is fundamental to understanding Miscanthus as a versatile energy crop. The abundance and mobilization of carbohydrates within grass stems are closely related to reproductive development. In sugarcane, concentrations of stem sucrose increase until the onset of flowering and are then utilized for the production of flowers and seeds [10]. After seed set, any remaining reserves are remobilized to the underground rhizome, therefore sugarcane is harvested before flowering is initiated [11]. Similarly in maize, stem carbohydrates accumulate until the mid-stage of grain filling and thereafter decline [12]. In a perennial species like Miscanthus, the timing of nutrient remobilization from the stems to the rhizome is important if shifting the timing of harvest to capture non-structural carbohydrates or other high value compounds is to be considered. If the rhizome was left depleted due to the removal of the stems too early in the season, this would seriously compromise the longterm sustainability of the crop. Therefore, the seasonal fluctuations in carbohydrates between organs will determine whether moving harvest dates forward may, or may not, be feasible or dependent upon genotype and growing environment.

Although grass species commonly store soluble sugars, amongst the plant kingdom the major resource storage carbohydrate is starch [13]. In soluble sugar-accumulating plants such as sugarcane, starch is also present in the green tissues but in very low quantities of $<0.5 \mathrm{mg} \mathrm{g}^{-1} \mathrm{FW}$, whereas switchgrass stores a greater abundance of starch in its stems than soluble sugars [14-16]. Miscanthus is more closely related to sugarcane than switchgrass and correspondingly Miscanthus $\times$ giganteus accumulates a greater concentration of sugars, rather than starch in its stems $[6,17,18]$. How reproductive development and climate impact on carbohydrate abundance and form has not been previously described.

A further plant process that has a major impact on carbohydrate dynamics is senescence. Senescence is the process by which the chloroplast is dissembled and stored nutrients are remobilized to developing seeds and/or storage organs [19]. For crop species, the timing of senescence is of importance because it has direct implications for canopy duration and quality [4]. In a biomass crop like Miscanthus, the longer the plant delays senescence, the longer it has to accumulate biomass. However, the process should take place before winter frosts kill off green leaves preventing nutrient remobilization as this phenomenon is thought to explain the poor performance of late senescing "stay-green" Miscanthus genotypes in Northern European locations [20]. As senescence marks the end of biomass accumulation and the translocation of soluble sugars from the stems to the rhizome, the timing of this process is important for both yield and composition of Miscanthus. It may also be reasonable to consider that different climates may be suited for producing Miscanthus for different end uses. For example, areas with colder winters may produce a drier crop and therefore be better for combustion whereas areas with warmer winters may be more suitable for fermentation owing to delayed senescence and the retention of moisture.

We aimed to uncover the following:

1. The seasonal timing of NSC dynamics between the rhizome and stems

2. The abundance of carbohydrates in the different organs through the year with a view to identifying if harvests may be brought forward to capture NSC without substantially depleting the rhizome.

3. The environmental and/or developmental triggers that caused or promoted NSC remobilization through senescence.

\section{Materials and Methods}

\section{Plant Material}

All genotypes used in this study are of Japanese origin. Miscanthus sinensis (EMI-11) is a diploid clone selected in 1988 from temperate Japan (Honshu Island) by Danish plant collector Dr. Poul Erik Brander. It was part of the European Miscanthus Improvement (EMI) programme (1997-2000) and is the female parent of the Mx2 mapping family [21]. M. sinensis (Goliath) is a triploid intraspecific hybrid of $M$. sinensis and was originally selected as a vigourous seedling from a cross (parents unknown) by Ernst Pagels and marketed as a "large-type" horticultural variety since the 1970s. Miscanthus sacchariflorus (Sac-5) is a tetraploid that was part of a seed population collected from central Japan, by TINPLANT, in 1992. It was also part of the EMI programme. Miscanthus $\times$ giganteus (Gig-311) is a naturally occurring triploid hybrid of diploid M. sinensis and a tetraploid M. sacchariflorus. It was supplied to Aberystwyth from Bical (Taunton) in 2005.

\section{Establishment of the Trials}

In May 2009, as part of the BSBEC-BioMASS project (http://www.bsbec-biomass.org.uk/), two dedicated trials were established at the Institute of Biological Environmental and Rural Sciences (IBERS), Aberyswyth, West Wales $\left(52.4139^{\prime} \mathrm{N},-4.014^{\prime} \mathrm{W}\right)$ and Rothamsted Research in Harpenden, South East England (51.82 N, 0.38 W). The trial, at both sites, was a randomised block design consisting of four blocks, each block containing four plots, one for each Miscanthus genotype described above. Each plot contained 121 plants with areas designated to: non-destructive measurements, annual yield harvest and destructive harvests. Plants 
designated for destructive harvest were surrounded by adjacent guard plants to prevent bordering effects after plants were harvested. Plants were grown from rhizome pieces cut from mature stands in modules before planting at a density of two plants per square meter. Surrounding each plot was a row of guard plants of the same genotype. The soil type at Aberystwyth is classified as a silty clay loam. The soil type at Harpenden is classified as a silty clay loam (18-27\% clay) with high flint content. Prior to the establishment of the BSBEC field trial, the Aberystwyth site was under grassland and the Harpenden site in cereal cultivation. Both sites were ploughed, power harrowed and then planted. The surrounding paths were then resown with grass.

\section{Climatic Measurements}

Meteorological measurements were monitored by on-site weather stations (Campbell Scientific) fitted with a CR1000 data-logger and a multiplexer that recorded air temperature at three heights above ground; Grass-tip, 20 and $150 \mathrm{~cm}$ and four depths below ground at $10,20,30$ and $60 \mathrm{~cm}$. Soil temperatures presented in this manuscript refer to the $10 \mathrm{~cm}$ depth. Incoming solar radiation, rainfall and wind speed were also recorded on-site at Aberystwyth whereas at Harpenden this data was obtained from the central weather station located $1.7 \mathrm{~km}$ from the site across flat ground. Mean air temperatures were calculated as the average of daily means for each time period (monthly in Fig. 1 and approximately fortnightly in Fig. 5). Mean minimum and maximum temperatures were calculated from the absolute maximum and minimum temperatures for each day, averaged over each time period.

\section{Field Observations}

Flowering was scored visually, twice per week from the last week of June. Measurements were made on four plants per plot. These values were then averaged on a per plot basis to provide a single value per plot to avoid pseudo replication. In all but one exception, all four replicate plots per genotype were scored, therefore $n=4$. The exception was plot 1 of Gig311 at Harpenden which failed to establish well and was therefore excluded from the experiment. Flowering was scored from the most developed stem on a four point scale as follows: 1 = flag leaf emergence, 2 = panicle emergence, $3=$ anthesis and $4=$ end of anthesis (no anthers remaining). The date at which $>50 \%$ of plants for each genotype had scored $>3.5$ was recorded. In 2011, senescence was scored visually from late September. Each plot was photographed weekly. Facing in an easterly direction at a distance of $2 \mathrm{~m}$, photographs were taken of the guard row in either a landscape or portrait orientation to capture as many plants as possible without cropping the top off the picture. Pictures were then assembled into a time-course collage for each plot at each site.
Photographs were then scored on a five-point scale for percentage greenness by four independent researchers. Each photograph was scored for greenness with $1=80-100 \%$ green, $2=60-80 \%$ green, $3=40-60 \%$ green, $4=$ $20-40 \%$ green and $5=<20 \%$ green. The average score for each plot was then calculated.

\section{Destructive Harvests}

Whole plants (above and below ground) were harvested in Feb 2011-Feb 2012 as follows: Plants within the designated destructive harvest area in each plot were assigned a number. Harvest sequence was then determined using a random number generator thereby assigning a particular individual to a specific harvest date. At each harvest, a single plant per plot was harvested $(n=3-4)$. It is recognised in a number of species, including Miscanthus, that strong diurnal changes in carbohydrates occur [22-24] and as both the above and below ground organs were to be harvested completing the harvest within a specific timeframe was important. To avoid confounding diurnal affects the sites were harvested over 2 days; on day one, blocks one and three were harvested and on day two, blocks two and four. All harvests were therefore completed in a two hour window either side of solar noon. For each destructively harvested plant, a single marked stem was harvested at $10 \mathrm{~cm}$ from the soil surface. The leaves were removed and the fresh weight of both stem and leaves were recorded separately before flash freezing in liquid $\mathrm{N}$ and storing on dry ice. The remaining total aboveground biomass was then harvested at $10 \mathrm{~cm}$, the material was chipped and a subsample taken, flash frozen and stored on dry ice until freeze drying. Rhizomes and the attached roots of the four genotypes were excavated. As M. sacchariflorus has a spreading rhizome morphology [25] a quadrat of $66.6 \times$ $75 \mathrm{~cm}$ was placed around the area of the original planting to ensure all rhizome was removed. Greater than $90 \%$ of Miscanthus rhizome and roots are located in the top $20 \mathrm{~cm}$ of soil [26] so we excavated to a depth of approximately $20 \mathrm{~cm}$. Rhizomes were washed to remove soil and stones and the below harvest mass was removed and recorded. Total rhizome was weighed before subsampling. All samples were weighed for moisture/dry matter content and prior to freeze drying were flash frozen in liquid nitrogen and stored on dry ice.

For the eight senescence specific harvests from July 2012 to December 2012 a single stem, representative of canopy height, was selected from the east facing outer guard row of each plot (as photographed for senescence quantification the previous year). As leaf abscission occurs during senescence and varies between genotype, leaf and stem were combined to make a single sample. Samples were flash frozen in liquid nitrogen prior to freeze drying. 
Fig. 1 Climatic data in 2011 and 2012 at Aberystwyth (Aber) and Harpenden (Harp). Rainfall (a), photosynthetically active radiation (b), air temperatures (c-f) and soil temperature (g). Temperature data (air and soil) with connective lines are average daily values $(\mathbf{c}-\mathbf{f})$ and the free symbols above and below the average maximum and minimum air temperatures show the absolute monthly maximum and minimum temperatures (c and e). Daily temperature range is the average maximum - average minimum monthly temperature (f). Underlined months show the destructive harvest time-points. On line graphs, Aber closed symbols and Harp open symbols

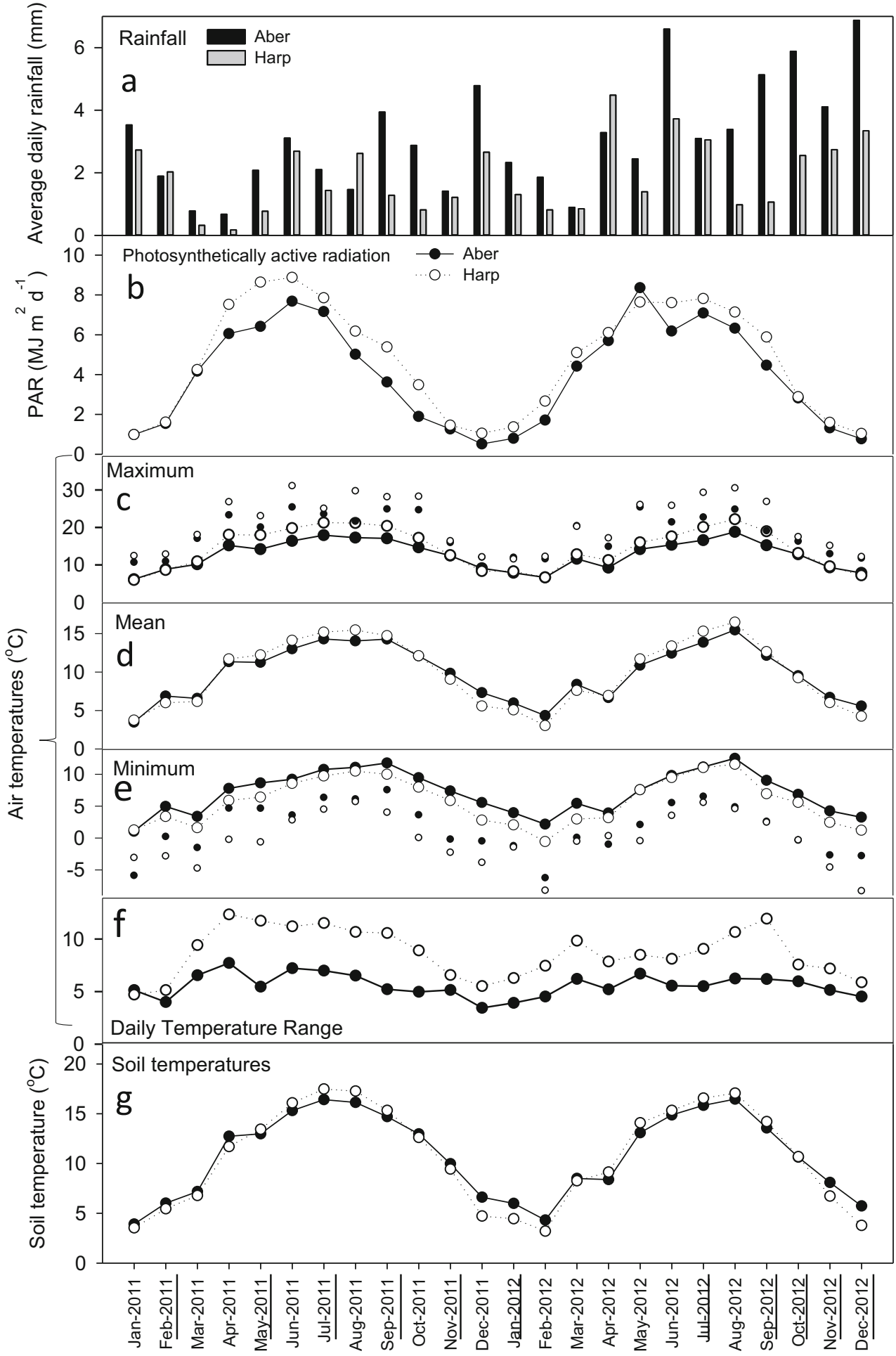

Month and Year
Carbohydrate Compositional Analyses

Soluble Sugar Extraction Approximately $20 \mathrm{mg}$ (actual weight recorded) of each cryomilled (Spex, Sampleprep 6870 Freezer Mill) plant tissue sample was weighed into
$2 \mathrm{ml}$ screw cap micro centrifuge tubes. Sugars were extracted four times with $1 \mathrm{ml}$ of $80 \%(v / v)$ ethanol; two extractions were at $80{ }^{\circ} \mathrm{C}$ for $20 \mathrm{~min}$ and $10 \mathrm{~min}$, respectively, and the remaining two at room temperature. The resulting supernatants were pooled. A $0.5-\mathrm{ml}$ aliquot of soluble sugar extract 
and the remaining pellet containing the insoluble fraction (including starch) were dried down in a centrifugal evaporator (Jouan RC 1022, Saint Nazaire, France) until all the solvent had evaporated. The dried-down residue from the soluble fraction was then resuspended in $0.5 \mathrm{ml}$ of distilled water. Samples were stored at $-20{ }^{\circ} \mathrm{C}$ for analysis.

Soluble Sugar Analysis Soluble sugars were quantified enzymatically by the stepwise addition of hexokinase (HXK), phosphoglucose isomerase (PGI) and invertase (INV) [27]. Samples were quantified photometrically by measuring the change in wavelength at $340 \mathrm{~nm}$ for $20 \mathrm{~min}$ after the addition of each enzyme. Sucrose, glucose and fructose were then quantified from a standard curve that was on the sample plate. Standards included on each plate for glucose were $0,1,2,3,4$ and $5 \mathrm{mM}$ and $0,0.5,1,1-5$, 2, $2.5 \mathrm{mM}$ for sucrose. For this report, the values of the hexoses and sucrose were combined to produce a total soluble sugar value.

Starch Quantification Starch was quantified using a modified Megazyme protocol (Megazyme Total Starch Assay Procedure, AOAC method 996.11, Megazyme International, Ireland). Briefly: the dried pellet was resuspended in $0.4 \mathrm{ml}$ of $0.2 \mathrm{M} \mathrm{KOH}$, vortexed vigorously and heated to $90{ }^{\circ} \mathrm{C}$ in a water bath for $15 \mathrm{~min}$ to facilitate gelatinization of the starch. A total of $1.28 \mathrm{ml}$ of $0.15 \mathrm{M} \mathrm{NaOAc}(\mathrm{pH} \mathrm{3.8)}$ ) was added to each tube (to neutralise the sample) before the addition of $20 \mu \mathrm{l} \alpha$-amylase and $20 \mu \mathrm{l}$ amyloglucosidase (Megazyme). After incubation at $50{ }^{\circ} \mathrm{C}$ for $30 \mathrm{~min}$ and centrifugation for $5 \mathrm{~min}$, a $0.02 \mathrm{ml}$ aliquot was combined with $0.6 \mathrm{ml}$ of GOPOD reagent (Megazyme). A total of $0.2 \mathrm{ml}$ of this reaction was assayed photometrically on a 96-well microplate at $510 \mathrm{~nm}$ against a water-only blank. Starch was quantified from a standard curve on the same plate. A series of D-glucose standards of $0,0.25,0.5$ and $1 \mathrm{mg} / \mathrm{ml}$ (from the stock provided in the kit) were included on each plate assayed. Each sample and standard was tested in duplicate. Each plate contained a control sample of known concentration for both soluble sugars and starch analysis.

\section{Chlorophyll}

Cryomilled samples of $\sim 20 \mathrm{mg}$ leaf + stem material were extracted in $2 \mathrm{ml} 80 \%(v / v)$ acetone and left in the dark for $30 \mathrm{~min}$. Samples were centrifuged at $15,000 \times \mathrm{g}$ for $5 \mathrm{~min}$ to pellet cellular debris. Supernatant was removed and measured using a spectrophotometer. Absorbance was measured at $663 \mathrm{~nm}$ and $646 \mathrm{~nm}$ to measure chlorophyll $a$ and $b$, respectively. Total chlorophyll $a$ and $b$ was determined using the following formulae: $(12.7 \times \mathrm{A} 663-2.69 \times \mathrm{A} 646) \times$ Volume/ Weight $=$ Chl a mg/g FW $+(22.9 \times$ A646-4.86 $\times$ A663 $) \times$ Volume/Weight $=$ Chl b mg/g FW [28].
Statistical Analyses

Statistical analyses were carried out using GenStat Version 16 (VSN International Ltd). For biomass statistics a two-way ANOVA was carried out for each genotype with month and site as fixed variables. Mixed-model ANOVAs were carried on the carbohydrate concentration data out to uncover differences between site, month and genotype and interactions therein. Site $\times$ genotype $\times$ month were considered fixed variables and block within month, for each site were random variables. Separate residuals were used for each site [29]. To identify correlations between carbohydrate concentration of the aerial and below ground organs with climate, Pearson's product-moment correlation coefficient analysis were carried out using SigmaPlot Version 12. For whole-plant destructive harvests, the mean concentration of carbohydrate (soluble sugar or starch) for each tissue type at each harvest point was compared to the mean climate data (e.g., PAR, maximum daily temperature, rainfall) in the 14 days preceding the harvest. The harvests points were closer together ( 10-14 days apart) during the 2012 senescence study, in which single stems were harvested, so climate data was averaged over the preceding 7 days. For each genotype, the carbohydrate and corresponding climate data from both sites were used in the Pearson's product-moment correlation coefficient analysis.

\section{Results}

Climatic Conditions and Plant Development at Aberystwyth and Harpenden

Throughout 2012, the average daily rainfall was generally greater at both sites compared to 2011 (Fig. 1a). Aberystwyth was the wettest site in both years but rainfall was low at both sites in March-April 2011. In reflection of the higher annual rainfall in 2012 the average daily photosynthetically active radiation (PAR) was lower (Fig. 1b). In both years, PAR was greater at Harpenden compared to Aberystwyth, with the exception of May 2012.

Considering mean monthly air temperature there appears to be little difference in air temperature between the two sites throughout the years of 2011 and 2012 (Fig. 1d). However, the average monthly maximum and minimum temperatures were higher and lower, respectively, at Harpenden (Fig. 1c, e). This is exemplified by Fig. If which shows the average daily temperature range (max-min) at the two sites. In both years, the average daily range was greater at Harpenden throughout the year, for example in May 2011 the average diurnal fluctuation was $12{ }^{\circ} \mathrm{C}$ at Harpenden and $5{ }^{\circ} \mathrm{C}$ at Aberystwyth (Fig. 1f). The degree of daily fluctuation was greatest in the spring-summer months and then declined into autumn and 
winter. These differences can be explained by the location of the two sites; the Aberystwyth site is located approximately $4 \mathrm{~km}$ from the west coast of the UK and therefore directly receives warm air currents from the Gulf Stream whereas Harpenden is in Eastern England and therefore more sheltered from this warming effect. The west coast of the UK is defined as being in hardiness zone 9 whereas most of the UK, including Harpenden, falls into hardiness zone 8 [30]. The hardiness zone classifies regions into the minimum temperature tolerance required for plant species to survive. To survive in zone 9 (Aberystwyth), a plant must be tolerant to $-7^{\circ} \mathrm{C}$ whereas zone 8 (Harpenden) requires tolerance to $-12{ }^{\circ} \mathrm{C}[30]$.

The soil temperatures were cooler at Harpenden than at Aberystwyth in early 2011 and 2012 (Fig. 1g). The soil temperatures then remained warmer at Harpenden until October in both years when they cooled more rapidly than at Aberystwyth. In November 2011, soil temperatures at Harpenden averaged approximately $5{ }^{\circ} \mathrm{C}$ whereas at Aberystwyth they averaged $7{ }^{\circ} \mathrm{C}$. The soil temperatures were cooler at Harpenden throughout the winter in both years.

\section{Carbohydrate Dynamics in the Rhizome and Harvestable Biomass}

Following the harvest in February 2011, the aboveground biomass increased from May and was generally similar within genotypes at both sites throughout the year (Table 1a). Most genotypes exhibited a reduction in biomass between peak yield (Nov) and harvest time (Jan-Feb) at one or both sites. This loss is due to the physical stresses exerted by the action of wind and frosts on the standing stems over winter.

At Harpenden, the rhizomes of Sac-5 and Gig-311 had a greater yield than those at Aberystwyth and EMI-11 rhizomes were larger from July 2011 onwards (Table 1b). The yield of Goliath rhizomes was similar at both sites.

The rhizomes contained very similar patterns of carbohydrate accumulation and abundance between the two sites (Fig. 2a, b). In all genotypes, at both sites, a decline in soluble sugars between February-May was observed when new stems were produced, but by July all genotypes had re-accumulated soluble sugars to concentrations equal or approaching those of February 2011 and January 2012.

The two M. sinensis genotypes maintained more consistent concentrations of rhizome soluble sugar throughout the year than Sac-5, and to a lesser extent Gig-311, which showed greater fluctuations in concentration (Fig. 2a).

At both sites, in all genotypes, a decline in rhizome starch was observed between February 2011 and May 2011 but the decline was greater at Aberystwyth in EMI-11 and Gig-311 (Fig. 2b). A notable difference in rhizome starch abundance between the two sites occurred between November 2011 and January 2012. At Aberystwyth Gig-311, Goliath and Sac-5 starch concentrations decreased in this time period whereas at
Harpenden they continued to increase. The same was not seen in EMI-11 which behaved consistently at both sites. The range of decline in starch during the winter at Aberystwyth was substantial; from $36 \%$ in Sac-5 to $55 \%$ in Goliath.

The re-accumulation of starch to winter (February 2011) levels took longer, but was comparable by September 2011. This demonstrates that the refilling of the rhizome with soluble photosynthate, and its subsequent conversion to starch, are not senescence-specific processes.

Following the annual cut-back in February 2011 an increase in soluble sugars in the newly grown total aboveground tissues was observed in all genotypes at both sites (Fig. 2c). The increase in soluble sugars in the regrowth period between February and May was greater at Harpenden, and the concentration of soluble sugars higher in May-July in all genotypes at Harpenden compared to Aberystwyth. After this time, however, soluble sugars rapidly declined in the total above ground at Harpenden to be equal to or lower than at Aberystwyth in September and almost down to February 2011 (previous winter) concentration by November. The sharp decline in soluble sugar between July and November at Harpenden was in contrast to that at Aberystwyth in which the decline was much more gradual. The concentration of soluble sugar in Sac-5 at Aberystwyth in November 2011 was $40 \mathrm{mg} \mathrm{g}^{-1}$ DW compared to only $9 \mathrm{mg} \mathrm{g}^{-1} \mathrm{DW}$ at Harpenden. The presence of soluble sugars in the total aboveground biomass in both February 2011 and January 2012 suggests that incomplete carbohydrate remobilization during winter may be a regular occurrence, in the four genotypes tested, when grown at Aberystwyth.

At Aberystwyth, the seasonal changes of starch abundance in the total above ground of EMI-11, Goliath and Sac-5 followed a similar pattern to soluble sugars (Fig. 2c, d). At Harpenden the pattern in EMI-11, Goliath and Sac-5 was also similar to the soluble sugars except concentrations fluctuated more in the main part of the growing season (May-September). Goliath was similar at both sites. Concentrations of starch in the total above ground of Gig-311 were comparatively low at both sites throughout the year. For all genotypes, starch concentrations above ground were more similar between sites than the soluble sugars.

The rapid decline in total aboveground soluble sugars from July and starch from September at Harpenden was indicative of an accelerated rate of senescence compared to Aberystwyth.

Only two genotypes flowered at both sites, the two M. sinensis genotypes, EMI-11 and Goliath (Fig. 2c). Both genotypes flowered slightly earlier at Harpenden, EMI-11 by 7 days and Goliath by 14 days. Gig-311 only flowered at Harpenden and later in the year than the other genotypes, in October.

To further investigate carbohydrate partitioning and seasonal dynamics within the total above ground, leaf and stem 
Table 1 Accumulation of biomass from 2011 to 2012 at Aberystwyth (Aber) and Harpenden (Harp)

\begin{tabular}{|c|c|c|c|c|c|c|c|c|}
\hline & \multicolumn{2}{|l|}{ EMI-11 } & \multicolumn{2}{|l|}{ Gig-311 } & \multicolumn{2}{|l|}{ Goliath } & \multicolumn{2}{|l|}{ Sac-5 } \\
\hline & Aber & Harp & Aber & Harp & Aber & Harp & Aber & Harp \\
\hline \multicolumn{9}{|c|}{ Biomass from the total above ground } \\
\hline Feb-11 & $78.7 \pm 9.9$ & $54.0 \pm 14.9$ & $161.5 \pm 96.2$ & $92.4 \pm 11.0$ & $70.4 \pm 27.4$ & $120.3 \pm 80.4$ & $91.2 \pm 46.3$ & $86.6 \pm 33.9$ \\
\hline May-11 & $20.5 \pm 7.8$ & $32.8 \pm 10.1$ & $55.6 \pm 28.9$ & $48.5 \pm 3.6$ & $25.5 \pm 12.7$ & $31.9 \pm 12.0$ & $7.8 \pm 3.8$ & $33.5 \pm 12.1$ \\
\hline Jul-11 & $276.7 \pm 97.7$ & $323.2 \pm 75.5$ & $218.6 \pm 99.0$ & $232.8 \pm 141.9$ & $220.5 \pm 172.1$ & $219.0 \pm 71.6$ & $163.8 \pm 88.7$ & $271.1 \pm 32.9$ \\
\hline Sep-11 & $300.2 \pm 120.8$ & $503.7 \pm 170.6$ & $999.6 \pm 251.1$ & $521.8 \pm 95.5$ & $508.1 \pm 233.3$ & $398.0 \pm 129.1$ & $456.9 \pm 107.1$ & $549.2 \pm 114.7$ \\
\hline Nov-11 & $297.1 \pm 89.0$ & $653.3 \pm 154.1$ & $849.5 \pm 174.2$ & $995.6 \pm 69.5$ & $688.5 \pm 249.0$ & $432.2 \pm 123.7$ & $396.2 \pm 118.5$ & $435.1 \pm 43.0$ \\
\hline Jan-12 & $205.0 \pm 66.6$ & $377.0 \pm 95.4$ & $457.3 \pm 201.1$ & $499.9 \pm 162.2$ & $521.3 \pm 32.4$ & $429.8 \pm 53.3$ & $227.9 \pm 86.5$ & $603.6 \pm 193.1$ \\
\hline \multicolumn{9}{|l|}{ F pr: } \\
\hline Month & $<0.001$ & & $<0.001$ & & $<0.001$ & & $<0.001$ & \\
\hline Site & 0.02 & & 0.49 & & 0.36 & & 0.05 & \\
\hline Month $\times$ site & 0.33 & & 0.38 & & 0.85 & & 0.38 & \\
\hline \multicolumn{9}{|c|}{ Biomass from rhizome } \\
\hline Feb-11 & $97.9 \pm 6.2$ & $86.2 \pm 25.7$ & $134.6 \pm 47.7$ & $238.7 \pm 30.7$ & $78.5 \pm 23.7$ & $119.2 \pm 63.2$ & $82.8 \pm 43.7$ & $297.0 \pm 107.0$ \\
\hline May-11 & $64.4 \pm 18.3$ & $114.2 \pm 33.4$ & $163.3 \pm 79.2$ & $286.2 \pm 51.1$ & $56.1 \pm 22.0$ & $89.2 \pm 29.2$ & $112.2 \pm 35.1$ & $223.0 \pm 60.9$ \\
\hline Jul-11 & $152.5 \pm 52.5$ & $146.2 \pm 30.0$ & $171.8 \pm 69.7$ & $231.5 \pm 89.0$ & $172.5 \pm 134.1$ & $130.5 \pm 27.5$ & $81.2 \pm 43.4$ & $437.6 \pm 31.8$ \\
\hline Sep-11 & $107.2 \pm 40.9$ & $206.9 \pm 55.3$ & $330.2 \pm 85.8$ & $603.3 \pm 74.0$ & $154.6 \pm 61.1$ & $154.5 \pm 40.2$ & $191.6 \pm 50.4$ & $552.3 \pm 68.6$ \\
\hline Nov-11 & $136.4 \pm 35.3$ & $363.2 \pm 82.2$ & $370.4 \pm 118.3$ & $1302.6 \pm 209.1$ & $251.6 \pm 92.9$ & $241.6 \pm 63.1$ & $197.0 \pm 46.7$ & $541.5 \pm 46.8$ \\
\hline Jan-12 & $138.7 \pm 37.1$ & $248.1 \pm 66.1$ & $375.4 \pm 193.4$ & $808.3 \pm 157.8$ & $348.3 \pm 41.4$ & $270.7 \pm 22.7$ & $316.0 \pm 96.4$ & $824.4 \pm 147.7$ \\
\hline \multicolumn{9}{|l|}{ F pr: } \\
\hline Month & $<0.008$ & & $<0.001$ & & 0.00 & & $<0.001$ & \\
\hline Site & 0.01 & & $<0.001$ & & 0.79 & & $<0.001$ & \\
\hline Month $\times$ site & 0.10 & & 0.01 & & 0.92 & & 0.15 & \\
\hline
\end{tabular}

Statistical analysis shows two-way ANOVAs (significant $\mathrm{F} \operatorname{Pr}=\leq 0.05$ ). $N=3-4 \pm \mathrm{SE}$

tissues were analysed separately. As few leaves were present in either February 2011 or January 2012, data is only shown from May to November (Fig. 3). In both leaf and stem, concentrations of soluble sugars were highest in all genotypes at Harpenden in May and then declined (Fig. 3a, b). In Harpenden, the stems contained a greater concentration of soluble sugars than the leaf at all time-points during the growing season, in all genotypes. This indicates that the stem acts as a sink organ for the source leaves during the growing season. At Aberystwyth, peak concentrations in both leaf and stem were lower and the rate of decline into autumn was also slower in Gig-311 and Sac-5. All genotypes at Aberystwyth contained higher amounts of soluble sugars in November compared to Harpenden.

The pattern of leaf starch accumulation was similar to that of leaf soluble sugar in EMI-11, Gig-311 and Sac-5, with peak accumulation being in May at Harpenden and then declining thereafter (Fig. 3c). Similarly to leaf soluble sugars, there was little change in leaf starch between May and July in these three genotypes at Aberystwyth; in EMI-11 and Sac-5, the concentration slightly increased in this period and in Gig-311 it slightly declined. The pattern of leaf starch accumulation in Goliath was similar between sites, showing an increase between May and July and then a decline.

The pattern of stem starch abundance was different to that of the leaves (Fig. 3d). Whereas starch abundance in the leaves was highest in spring-summer and then declined, concentrations in the stems rose to a maximum in September in EMI-11, Gig-311 and Sac-5 at both sites. Goliath also showed this same trend at Aberystwyth but reached maximum starch concentration in July at Harpenden. This suggests that from midsummer into the senescence period, soluble sugars were exported out of the leaves and transiently stored as starch in the stems. Maximum concentrations of starch (September) were higher at Harpenden but in November concentrations of starch in leaf and stems were higher at Aberystwyth (Fig. 3c, d).

In November 2011, the retention of carbohydrates in the stems and leaves of the four genotypes, particularly in Gig311 and Sac-5 at Aberystwyth, meant that the total NSC concentration in these two genotypes was approximately $5 \%$ DW at this site. 

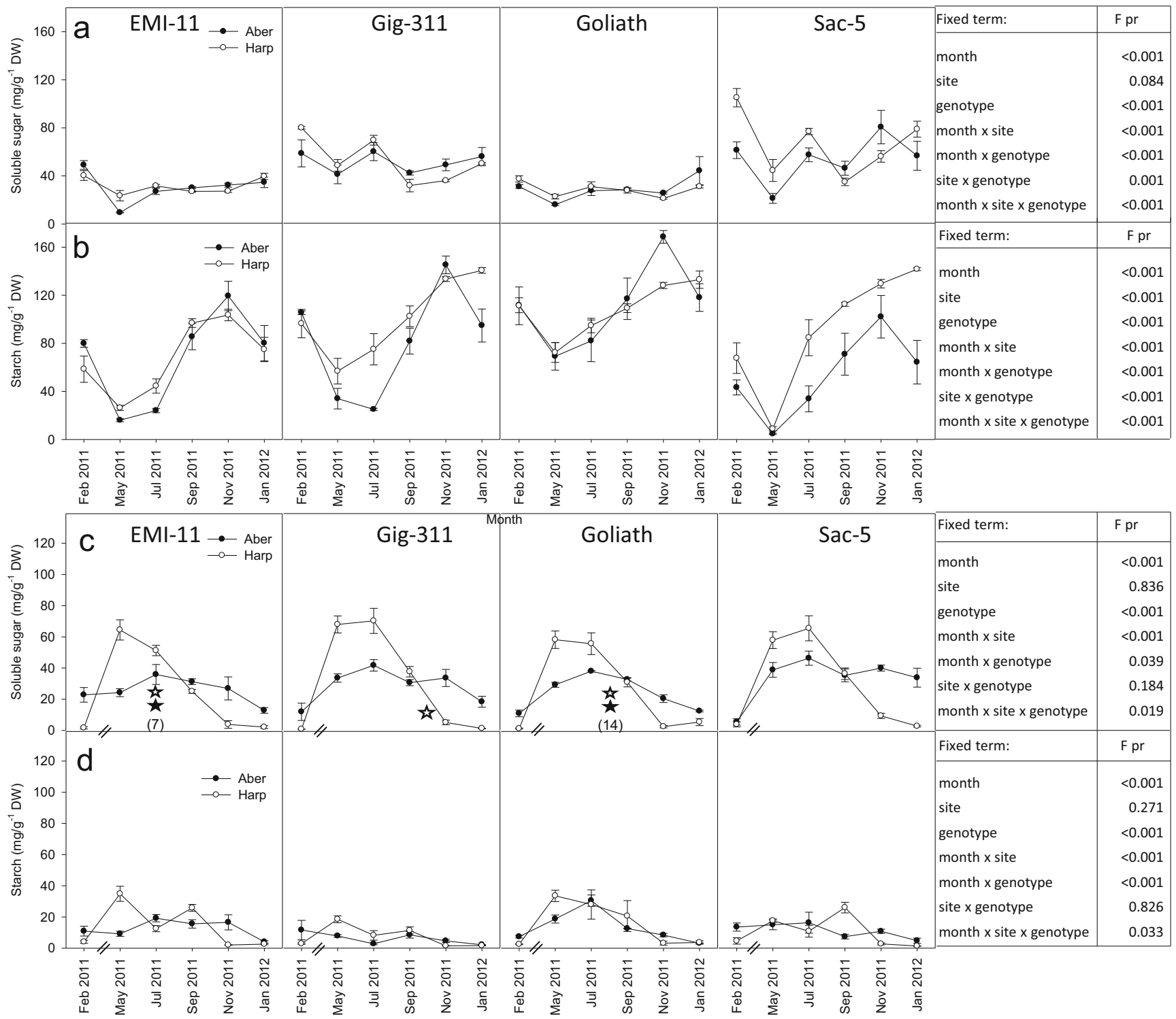

Fig. 2 Carbohydrate dynamics in the rhizome and total above ground. Total concentration of soluble sugars (a) and starch (b) in the rhizome and concentration of soluble sugars (c) and starch (d) in the total above ground in 2011-2012. Statistical analysis shows the results of mixed model ANOVA (Significant FPr $=\leq 0.05$ ). Flowering time is indicated above the respective month for each genotype in which flowering

\section{Quantification of Senescence}

Visual scoring of chlorophyll loss from October to December 2011 revealed that, as with carbohydrates, the loss of chlorophyll was more rapid at Harpenden than Aberystwyth (Fig. 4a).

To uncover why senescence was accelerated at Harpenden in 2011 and whether a more rapid rate of chlorophyll loss and carbohydrate remobilization was an annual occurrence, we carried out a series of harvests every 2 weeks throughout the senescence period in 2012 . occurred (c), the order of the stars indicates at which site flowering first occurred with the earlier site being located above the later site, the difference in timing in days is stated in parentheses. Flowering scores show when $>50 \%$ of plants were in anthesis $N=3-4, \mathrm{SE} \pm 1$ : filled stars indicate Aberystwyth and open stars indicate Harpenden

The quantification of chlorophyll in July and throughout senescence in 2012 revealed that total chlorophyll concentrations were lower at Harpenden even in July, but the differences became greater during the senescence period in all genotypes (Fig. 4b). The greatest difference between sites was in EMI-11 in which chlorophyll concentration at Harpenden was 1/3 that of Aberystwyth in Early September. At the end of the senescence period in 2012, the amount of chlorophyll left in the stems was greater at Aberystwyth in all genotypes.

In July 2012, and throughout the senescence period, the climate was typical of the two regions; rainfall was higher at 

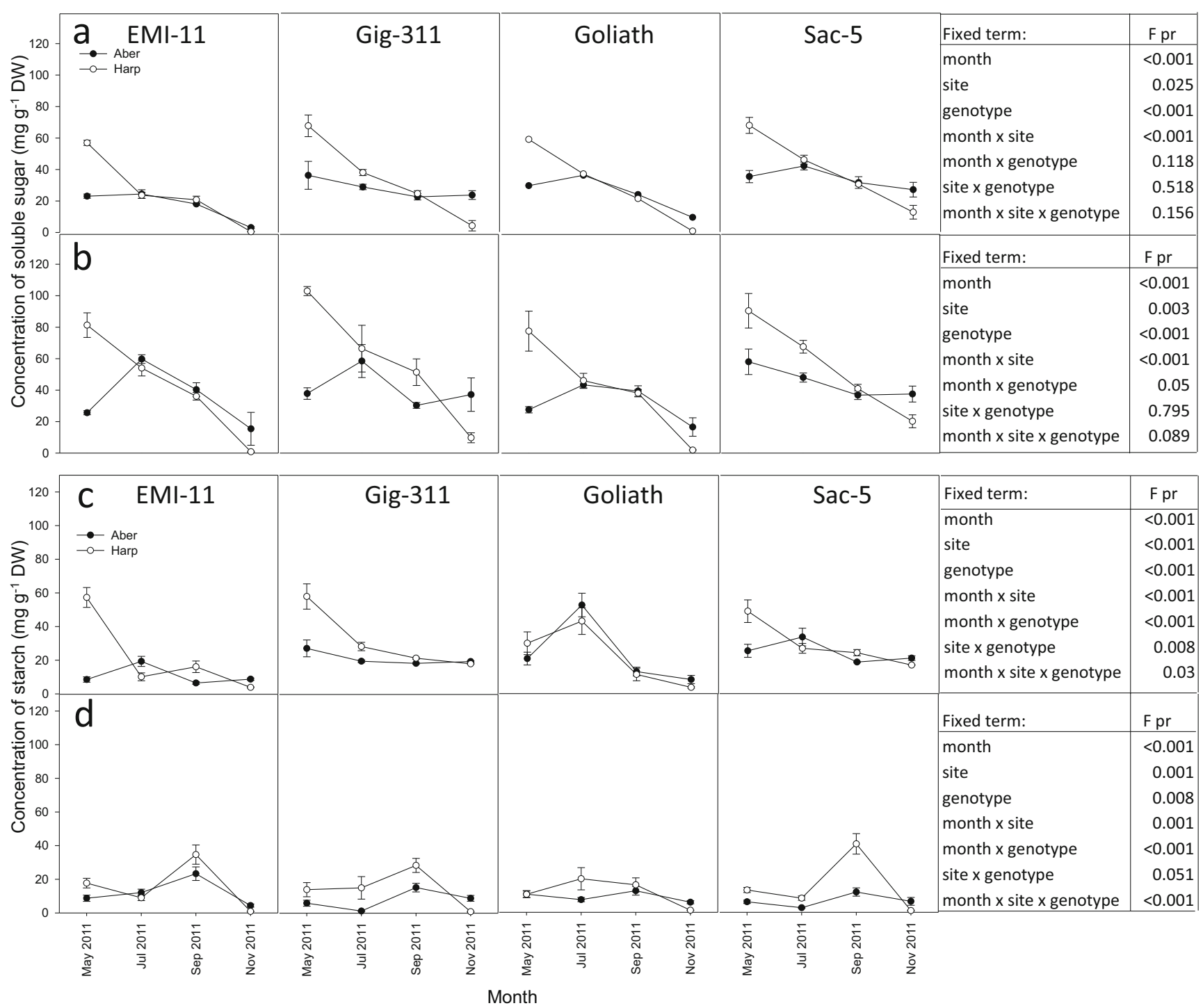

Fig. 3 Concentration of soluble sugar in the leaf (a) and stem (b) and concentration of starch in the leaf (c) and stem (d) at Aberystwyth (Aber) and Harpenden (Harp) in 2011. Statistical analysis shows the results of mixed model ANOVA (Significant F $\operatorname{Pr}=\leq 0.05$ ). $n=3-4, \mathrm{SE} \pm 1$

Aberystwyth and PAR was lower (Fig. 5a, b). At Harpenden, the maximum air temperatures were higher at all time-points except one (late Oct), minimum temperatures were consistently lower, the mean was generally similar and the daily range in temperatures was greater throughout (Fig. 5c).

Soluble sugar abundance did not change as appreciably between July and September 2012 in any genotype, at either site as it had in 2011. However, similarly to 2011, from October to November, all genotypes showed a more rapid reduction of soluble sugar at Harpenden than at Aberystwyth (Fig. 5d). The sharpest period of decline at Harpenden was Mid-Late October which correlated with a drop in maximum temperature of $4{ }^{\circ} \mathrm{C}$ in (Fig. $5 \mathrm{c}$ ). The trend showed that soluble sugars were retained for longer and at the end of the experiment levels of soluble sugar were higher in all genotypes, except Sac-5, at Aberystwyth. The concentration of starch increased in the stems during senescence (Fig. 5e) as had been observed in 2011 and also reported in M. × giganteus plants grown in the Midwestern USA [18]. The rate of starch decline was more rapid at Harpenden particularly through the month of October. The most rapid changes were seen in Gig-311, EMI-11 and Sac-5 and the least different between sites was Goliath.

Similarly to 2011, NSC were still present at the end of the experiment to the greatest extent in Gig-311 at Aberystwyth where concentrations were approximately $7 \%$ in November and $5 \%$ in December. In Sac-5, carbohydrate concentrations were approximately $5 \%$ in November and December at both sites (Fig. 5).

Only two genotypes flowered at either site in 2012, EMI-11 and Goliath. Unlike the previous year, no differences in flowering time were observed between sites (Fig. 5f), 

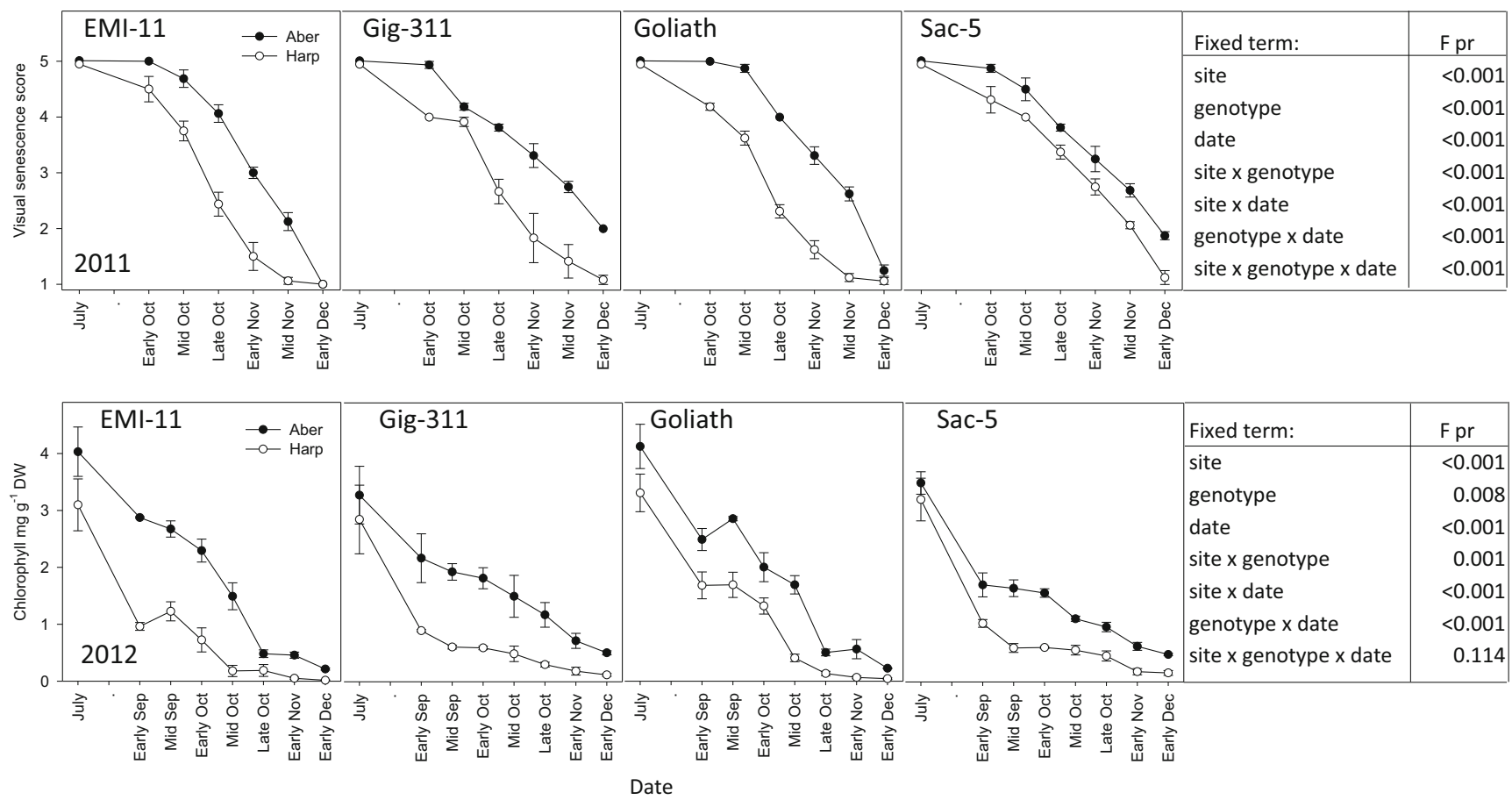

Fig. 4 Chlorophyll loss during senescence in 2011 and 2012. In 2011, the progression of chlorophyll loss was scored visually throughout the senescence period (October-December) (a). In 2012, chlorophyll

probably owing to the wet summer conditions at both sites. This demonstrates that accelerated senescence was observed both years at Harpenden and occurred irrespective of flowering.

Correlation Between Climate and Carbohydrate Abundance in the Aboveground Organs

Pearson's correlations were carried out to uncover relationships between carbohydrate abundance in the different organs and climatic variables (Fig. 6a-c).

A strong negative relationship between rhizome starch and PAR was observed in all genotypes, except Sac-5 (Fig. 6a). Negative relationships between TAG carbohydrates (sugars or starch) and the rhizome were present in Gig-311, Goliath and Sac-5. In all genotypes, strong positive correlations between PAR, maximum temperature, temperature range and TAG soluble sugars were detected. In all genotypes, except EMI11 a weaker, but significant correlation was also present between soluble sugars and minimum temperature. TAG starch also positively correlated with PAR and temperature range in all genotypes except Sac-5 and maximum temperature correlated with TAG starch in all genotypes except Gig311.

There were strong, positive correlations between leaf soluble sugars, leaf starch and stem soluble sugars in all genotypes (Fig. 6b). No correlations between carbohydrates in the leaf and starch in the stem were detected in any of the genotypes. concentration was quantified in midsummer (July) and throughout the senescence period (b). Statistical analysis shows the results of mixed model ANOVA (Significant F Pr $=\leq 0.05$ ). $N=3-4 \pm \mathrm{SE}$

A strong positive correlation between PAR and soluble sugars in the leaf and PAR and soluble sugars in the stem was observed in all genotypes (Fig. 6b). In Gig-311 and Sac-5, a positive correlation between leaf starch and PAR was also present. Minimum temperatures did not significantly correlate with either leaf or stem carbohydrates. Maximum temperature strongly positively correlated with stem solubles in all genotypes except Sac-5 but stem starch only significantly correlated with maximum temperature in Goliath, however, nonsignificant correlation coefficients of $\sim 0.5-0.7$, were detected in the other genotypes. The daily range in temperatures correlated strongly with soluble sugars but only with starch in Gig-311.

The main change in climate and carbohydrate correlation during senescence was that the daily minimum and maximum temperature correlated equally with soluble sugars in both EMI-11 and Goliath and also with starch, whereas only maximum temperatures correlated with carbohydrates throughout the year (Fig. 6b, c). This suggests that minimum temperatures have a greater effect during senescence than over the growing season as a whole. Correlations between carbohydrate abundance and climate were fewer and weaker for Gig-311 and Sac-5. Interestingly, the only correlation between starch and climate in Gig-311 and Sac-5 was with daily temperature range suggesting that this impacts on starch abundance more greatly than absolute maximum or minimum temperatures. 

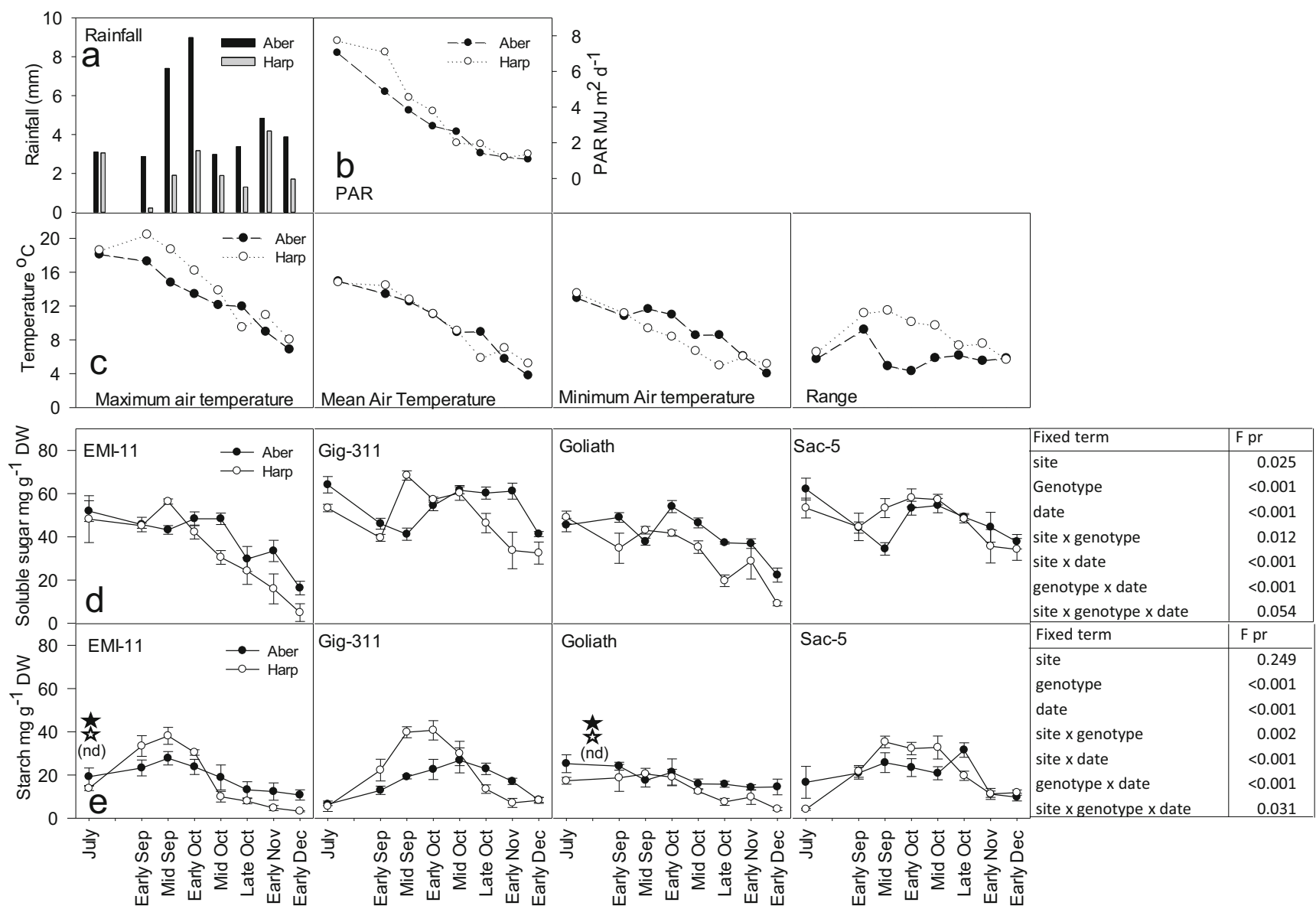

Fig. 5 Climate and carbohydrate remobilization during senescence in 2012. Rainfall (a) and photosynthetically active radiation (PAR) (b), temperature parameters (left to right: average daily maximum, average daily mean, average daily minimum, average daily range) (c), concentration of soluble sugars (d) and starch (e) in the stem + leaf. Statistical

\section{Discussion}

Non-structural Carbohydrates Dynamics and Flowering

A number of studies from related $\mathrm{C} 4$ energy crops such as maize, sorghum and sugarcane refer to a progressive increase in stem soluble sugars as stems age and particularly until flowering [31-33]. In our study, even though our genotypes represented flowering and non-flowering types, no increase in the concentration of soluble sugar in the stem was observed as the plants aged or flowered in 2011. However, a relationship between flowering and carbohydrate metabolism is hinted at in the results. In Sac-5, the non-flowering genotype, soluble sugars were still present in the leaf tissues in November at both sites in 2011 and 2012 and in Gig-311, which only flowered at Harpenden in 2011, soluble sugars were present in the leaf tissues at Aberystwyth only in 2011 and both sites in 2012 . This suggests that a proportion of soluble sugars are retained in the leaf tissues until flowering when they are remobilized into the stem, probably to support panicle growth. Unlike analysis shows mixed model ANOVAs (significant $\mathrm{F} \operatorname{Pr}=\leq 0.05$ ). $N=3-4$ \pm SE. The timing of flowering in 2012 is shown (e), no differences $(n d)$ in flowering time between sites were observed in 2012. Filled stars indicate Aberystwyth and open stars indicate Harpenden

soluble sugars, starch accumulated into autumn as has been previously reported in aging stems [18]. As this accumulation occurred in flowering and non-flowering genotypes alike, we conclude that the increase and subsequent decline of stem starch in autumn is not induced by flowering but by environmental cues.

Winter Temperature Affects Starch Abundance in the TAG and Rhizome

The positive correlation between leaf and stem carbohydrates and diurnal temperature range is intriguing. Daily maximum temperatures generally occur in the middle of the day, when carbohydrates are accumulating whereas the daily minimum generally coincides with pre-dawn when starch reserves are being metabolised [13]. The diurnal range therefore is indicative of the rate of night-time cooling. In Arabidopsis, the metabolism of starch has been shown to be buffered against low night temperatures [34], but Arabidopsis is a chillingtolerant species whereas Miscanthus is more sensitive and 

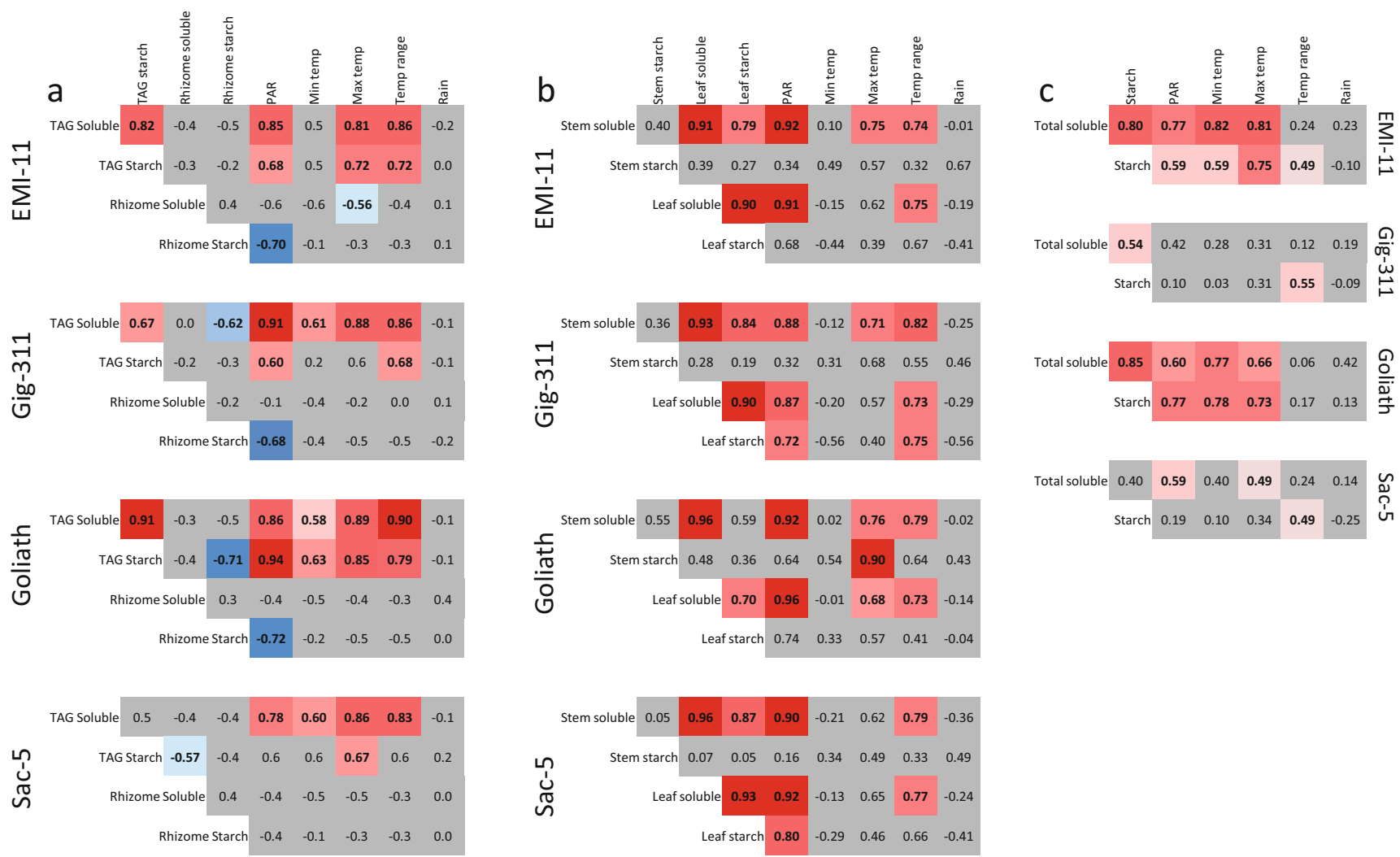

Fig. 6 Heat map showing Pearson's correlation coefficients between carbohydrate abundance in total above ground $(T A G)$, rhizome and climate data throughout the year in 2011-2012 (a), the leaf and stem and climate data in May-Nov 2011 (b) and marked stem (stem and leaf) during midsummer (July) and the senescence period (Sep-Dec) in 2012

many genotypes, such as Sac-5, have evolved in environments that do not incur chilling temperatures [25]. Therefore, it is possible that more rapid night-time cooling inhibits the activity of starch metabolising enzymes resulting in a greater retention of leaf starch. If this is the case, it could be expected to have a negative impact on growth [35].

The striking similarity between the seasonal dynamics and abundances of carbohydrate in the rhizomes of the different genotypes between the two experimental sites shows that the rhizome is far less exposed to rapid fluctuations in environment than the aboveground organs. Seasonal fluctuations in nitrogen within the rhizomes of $M$. $\times$ giganteus $\left(6-9 \mathrm{gN} \mathrm{kg}^{-1}\right)$ were smaller than those observed in the above-ground biomass (5-15 $\mathrm{g} \mathrm{N} \mathrm{kg}^{-1}$ ) [36]. A major difference in rhizome starch abundance between the sites was observed between November and January; in all genotypes, except EMI-11, starch concentrations declined at Aberystwyth but increased or remained constant at Harpenden. An explanation for this observation comes from the soil temperatures which were warmer at Aberystwyth over the winter months. In Pinus taeda L. (loblolly pine), temperature controls most of the variation in stem and branch maintenance respiration rate during the period of winter dormancy [37]. As the soil (c). Data from both sites were combined for each analysis. Correlation coefficient values are shown inside the boxes. Significant positive correlation coefficients $(P=\leq 0.05)$ are shown in red hues, negative correlation coefficients are shown in blue hues and non-significant correlations are coloured grey

temperatures were warmer during winter at Aberystwyth, it is likely that the respiration rates of the rhizomes were higher accounting for the decline in carbohydrate reserves. It is possible that this is a detrimental feature of growth at Aberystwyth, and indeed other areas with similar winter temperatures, as reserves expended over winter will not be available to fuel growth the following spring.

Of interest to the timing of harvests is the refilling of the rhizome with photosynthate following the decline in spring when new stems are produced. In all four genotypes, rhizome starch reserves were at least equal to the previous winter's levels (pre stem emergence in February 2011) by November, therefore harvesting after this time would not leave the rhizome depleted of carbohydrates. However, the effect on other nutrient dynamics, such as $\mathrm{N}, \mathrm{P}$ and $\mathrm{K}$ would have to be determined.

The Rate of Senescence is Controlled by Daily Minimum Temperature

In our study, we observed that senescence was initiated earlier in the year and progressed more rapidly at Harpenden compared to Aberystwyth. In Populus tremula (European Aspen) 
the initiation of senescence is controlled by day length but the rate of progression is driven by temperature [38]. As chlorophyll abundance had declined in all genotypes at both sites from July it is therefore reasonable that this decline was triggered by day length but the subsequent rates of decline were driven by temperature. In EMI-11, Gig-311 and Goliath, the decline in soluble sugars and/or starch started from MidSeptember at Harpenden even though maximum daily temperatures were higher and mean temperatures were similar to Aberystwyth. The most rapid rate of decline in all genotypes at Harpenden occurred during mid-October which corresponded to a sharp drop in minimum air temperature. Therefore, it appears that the accelerated rate of senescence at Harpenden was caused by the lower daily minimum temperatures in early autumn and the warmer daily maximum temperatures could not counteract this effect.

It should be noted however, that the daily minimum temperatures in October were similar to those experienced in May. Why then should senescence have been promoted by these temperatures in October but not in May? In species as diverse as Arabidopsis and Aspen, a relationship between maturity and competency to senescence has been reported [38, 39]. Therefore, it appears that similarly to Arabidopsis and Aspen, senescence promoting conditions will not trigger senescence in Miscanthus until a minimum developmental stage has been reached.

The difference in timing of senescence between the two sites was not great enough to have an impact on yield, but may have more substantial implications for harvesting Miscanthus for non-structural carbohydrates. At the end of the senescence experiment on 03/12/12, Gig-311 and Sac-5 both still contained approximately $5 \%$ non-structural carbohydrate (soluble sugar and starch) in their stem tissues at both sites. The first frost event to less than $-2{ }^{\circ} \mathrm{C}$ occurred at both sites on $28 / 11 / 12$. After a frost event at $-2{ }^{\circ} \mathrm{C}$, all greenness was found to be lost from five genotypes of Miscanthus growing in Germany and the authors concluded that at this temperature leaves had been killed [25]. If the aboveground organs were killed at the end of November, presumably any carbohydrates still within them were not remobilized back to the rhizome but either stayed in the stems or were degraded by microbial activity over winter. Although incomplete senescence is probably detrimental to the nutrient balance of the plant, Gig-311 has been shown to be highly productive in Europe and USA $[40,41]$. This therefore presents a possibility; if the sustainability of Gig-311 (or other genotypes) is not compromised by incomplete senescence, harvest time could be brought forward to November/December to capture the non-structural carbohydrates that are more readily fermentable than cellulose. In November 2011 and 2012, Gig-311 contained approximately 5-7 \% non-structural carbohydrate (soluble sugar $~ 5 \%$ and $\sim 2 \%$ starch). The annual yield of $M \times$ giganteus in the UK is $\sim 14 \mathrm{t} \mathrm{ha}^{-1}$ [26]; this equates to a potential yield of $0.7-1 \mathrm{t} \mathrm{ha}^{-1}$ of non-structural carbohydrate in regions with average minimum temperatures in September-October of approximately $\geq 8^{\circ} \mathrm{C}$. The possibility of using Miscanthus as a "temperate sugarcane" has been previously suggested [18] as concentrations of $5 \%$ soluble sugar are similar to the sugarcane progenitors $[42,43]$. Here, we show that these levels persist in Gig-311 and Sac-5 into winter when chlorophyll levels have declined $\sim 70 \%$ from summer values. Therefore, with concerted breeding efforts, the late-season, non-structural carbohydrate concentration could be targeted for improvement as has been spectacularly achieved with sugarcane and temperate ryegrass $[43,44]$. Studies are currently underway to determine the abundance of essential elements in the aboveground organs in November and harvest time (February) to determine the quantity of nutrient that is likely to be removed if harvest time was brought forward.

In conclusion, our study has uncovered that: unlike sorghum or sugarcane, the accumulation of stem carbohydrates in Miscanthus is not dependent on flowering. Aboveground soluble sugars are converted to starch during periods of reducing temperatures (autumn). The rate of senescence is determined by the daily minimum temperatures and higher daily maximums do not counteract this effect. The rhizome contains concentrations of carbohydrate comparable to winter maximums by November. This suggests that harvests could be moved to late autumn/early winter without depleting rhizome carbohydrate reserves in the UK. The retention of carbohydrates in the stems of some genotypes after the first frost may provide a readily fermentable source of soluble sugar and starch for biofuel production and should be targeted for crop improvement through breeding.

Acknowledgments We would like to extend our thanks to Ruth Sanderson for her assistance with the statistical analyses. This work was supported by the BBSRC Sustainable Bioenergy Centre (BSBEC) grant (BB/G016216/1) working within the BSBEC-BioMASS (http://www. bsbec-biomass.org.uk/) Programme of the centre, the BBSRC Energy Grasses \& Biorefining Institute Strategic Programme (BBS/E/W/ 00003134) at IBERS and the Cropping Carbon Institute Strategic Programme at RRes and Ceres Inc.

Open AccessThis article is distributed under the terms of the Creative Commons Attribution License which permits any use, distribution, and reproduction in any medium, provided the original author(s) and the source are credited.

\section{References}

1. Visser P, Pignatelli V (2001) Utilization of Miscanthus in: Miscanthus: for energy and fibre. In: Walsh MBJaM (ed) Miscanthus: for energy and fibre: earthscan, 2001. pp. 109-154

2. Hodgson EM, Fahmi R, Yates N, Barraclough T, Shield I et al (2010) Miscanthus as a feedstock for fast-pyrolysis: does agronomic treatment affect quality? Bioresour Technol 101:6185-6191 
3. Somerville C, Youngs H, Taylor C, Davis SC, Long SP (2010) Feedstocks for lignocellulosic biofuels. Science 329:790-792

4. Robson P, Mos M, Clifton-Brown J, Donnison I (2012) Phenotypic variation in senescence in Miscanthus: towards optimising biomass quality and quantity. Bioenergy Res 5:95-105

5. McKendry P (2002) Energy production from biomass (part 1): overview of biomass. Bioresour Technol 83:37-46

6. Hodkinson TR, Chase MW, Lledo MD, Salamin N, Renvoize SA (2002) Phylogenetics of Miscanthus, Saccharum and related genera (Saccharinae, Andropogoneae, Poaceae) based on DNA sequences from ITS nuclear ribosomal DNA and plastid trnL intron and trnL-F intergenic spacers. J Plant Res 115:381-392

7. Karp A, Shield I (2008) Bioenergy from plants and the sustainable yield challenge. New Phytol 179:15-32

8. Allison GG, Morris C, Clifton-Brown J, Lister SJ, Donnison IS (2011) Genotypic variation in cell wall composition in a diverse set of 244 accessions of Miscanthus. Biomass Bioenergy 35:4740-4747

9. Lygin AV, Upton J, Dohleman FG, Juvik J, Zabotina OA et al (2011) Composition of cell wall phenolics and polysaccharides of the potential bioenergy crop-Miscanthus. Global Change Biol Bioenergy 3:333-345

10. Slewinski TL (2012) Non-structural carbohydrate partitioning in grass stems: a target to increase yield stability, stress tolerance, and biofuel production. J Exp Bot 63:4647-4670

11. Komor E (2000) The physiology of sucrose storage in sugarcane. In: Gupta AM, Kaur N (eds) Carbohydrate reserves in plants - synthesis and regulation. Elsevier, New York, pp 35-53

12. Hume DJ, Campbell DK (1972) Accumulation and translocation of soluble solids in corn stalks. Can J Plant Sci 52:363-368

13. Zeeman SC, Kossmann J, Smith AM (2010) Starch: its metabolism, evolution, and biotechnological modification in plants. Annu Rev Plant Biol 61(61):209-234

14. Ferreira SJ, Kossmann J, Lloyd JR, Groenewald JH (2008) The reduction of starch accumulation in transgenic sugarcane cell suspension culture lines. Biotechnol J 3:1398-1406

15. Smith D (1975) Trends of nonstructural carbohydrates in the stem bases of switchgrass. J Range Manag 28:389-391

16. Scofield GN, Ruuska SA, Aoki N, Lewis DC, Tabe LM et al (2009) Starch storage in the stems of wheat plants: localization and temporal changes. Ann Bot 103:859-868

17. Burner DM, Tew TL, Harvey JJ, Belesky DP (2009) Dry matter partitioning and quality of Miscanthus, Panicum, and Saccharum genotypes in Arkansas, USA. Biomass Bioenergy 33:610-619

18. de Souza AP, Arundale RA, Dohleman FG, Long SP, Buckeridge MS (2013) Will the exceptional productivity of Miscanthus $\mathrm{x}$ giganteus increase further under rising atmospheric CO2? Agric For Meteorol 171:82-92

19. Himelblau E, Amasino RM (2001) Nutrients mobilized from leaves of Arabidopsis thaliana during leaf senescence. J Plant Physiol 158: $1317-1323$

20. Clifton-Brown JC, Lewandowski I, Andersson B, Basch G, Christian DG et al (2001) Performance of 15 Miscanthus genotypes at five sites in Europe. Agron J 93:1013-1019

21. Ma XF, Jensen E, Alexandrov N, Troukhan M, Zhang LP et al (2012) High resolution genetic mapping by genome sequencing reveals genome duplication and tetraploid genetic structure of the diploid Miscanthus sinensis. Plos One 7:e33821

22. Sicher RC, Kremer DF, Harris WG (1984) Diurnal carbohydrate metabolism of barley primary leaves. Plant Physiol 76:165-169

23. Hendrix DL, Huber SC (1986) Diurnal fluctuations in cotton leaf carbon export, carbohydrate content, and sucrose synthesizing enzymes. Plant Physiol 81:584-586

24. Purdy SJ, Maddison AL, Jones LE, Webster RJ, Andralojc J et al (2013) Characterization of chilling-shock responses in four genotypes of Miscanthus reveals the superior tolerance of M. x giganteus compared with M. sinensis and M. sacchariflorus. Ann Bot 111:999-1013

25. Clifton-Brown JC, Lewandowski I (2000) Overwintering problems of newly established Miscanthus plantations can be overcome by identifying genotypes with improved rhizome cold tolerance. New Phytol 148:287-294

26. Clifton-Brown JC, Breuer J, Jones MB (2007) Carbon mitigation by the energy crop, Miscanthus. Glob Chang Biol 13:2296-2307

27. Jones MG, Outlaw WH, Lowry OH (1977) Enzymic assay of 10 to 10 moles of sucrose in plant tissues. Plant Physiol 60:379-383

28. Chang CSJ, Li YH, Chen LT, Chen WC, Hsieh WP et al (2008) LZF1, a HY5-regulated transcriptional factor, functions in Arabidopsis de-etiolation. Plant J 54:205-219

29. Payne RWS, Harding S (2013) A guide to REML in GenStat ${ }^{\mathbb{R}}$ (16th Edition) http://www.genstat.co.uk/. VSN International, 5 The Waterhouse, Waterhouse Street, Hemel Hempstead, Hertfordshire HP1 1ES, UK

30. USDA Plant Hardiness Zone Map ARS, U.S. Department of Agriculture (2012). Accessed from http://planthardiness.ars.usda. gov. Plant Hardiness Zone Map, 2012. Agricultural Research Service, US Department of Agriculture

31. Vietor DM, Miller FR, Cralle HT (1990) Nonstructural carbohydrates in axillary branches and main stem of senescent and nonsenescent sorghum types. Crop Sci 30:97-100

32. Mcbee GG, Miller FR (1993) Stem carbohydrate and lignin concentrations in sorghum hybrids at 7 growth-stages. Crop Sci 33:530-534

33. Lingle SE (1997) Seasonal internode development and sugar metabolism in sugarcane. Crop Sci 37:1222-1227

34. Pyl ET, Piques M, Ivakov A, Schulze W, Ishihara H et al (2012) Metabolism and growth in arabidopsis depend on the daytime temperature but are temperature-compensated against cool nights. Plant Cell 24:2443-2469

35. Graf A, Smith AM (2011) Starch and the clock: the dark side of plant productivity. Trends Plant Sci 16:169-175

36. Dohleman FG, Heaton EA, Arundale RA, Long SP (2012) Seasonal dynamics of above- and below-ground biomass and nitrogen partitioning in Miscanthus $\mathrm{x}$ giganteus and Panicum virgatum across three growing seasons. Global Change Biol Bioenergy 4:534-544

37. Maier CA, Zarnoch SJ, Dougherty PM (1998) Effects of temperature and tissue nitrogen on dormant season stem and branch maintenance respiration in a young loblolly pine (Pinus taeda) plantation. Tree Physiol 18:11-20

38. Fracheboud Y, Luquez V, Bjorken L, Sjodin A, Tuominen H et al (2009) The control of autumn senescence in European aspen. Plant Physiol 149:1982-1991

39. Weaver LM, Amasino RM (2001) Senescence is induced in individually darkened Arabidopsis leaves but inhibited in whole darkened plants. Plant Physiol 127:876-886

40. Lewandowski I, Clifton-Brown JC, Scurlock JMO, Huisman W (2000) Miscanthus: European experience with a novel energy crop. Biomass Bioenergy 19:209-227

41. Dohleman FG, Long SP (2009) More productive than maize in the midwest: how does Miscanthus do it? Plant Physiol 150: 2104-2115

42. Wang DF, Portis AR, Moose SP, Long SP (2008) Cool C(4) photosynthesis: Pyruvate $\mathrm{P}(\mathrm{i})$ dikinase expression and activity corresponds to the exceptional cold tolerance of carbon assimilation in Miscanthus x giganteus. Plant Physiol 148:557-567

43. Lingle SE, Viator RP, Johnson RM, Tew TL, Boykin DL (2009) Recurrent selection for sucrose content has altered growth and sugar accumulation in sugarcane. Field Crop Res 113:306-311

44. Wilkins PW, Lovatt JA (2011) Gains in dry matter yield and herbage quality from breeding perennial ryegrass. Ir J Agric Food Res 50:23-30 